\title{
Methods to Evaluate the Eggshell Quality of Table Eggs
}

http://dx.doi.org/10.1590/1806-9061-2019-1046

\section{-Author(s)}

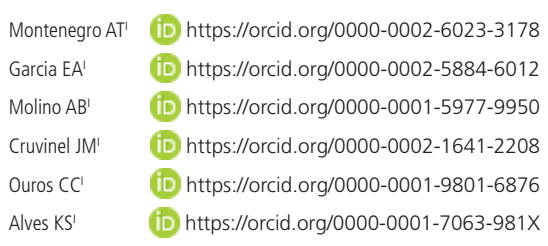

Animal Production Department, School of Veterinary Medicine and Animal Science, São Paulo State University (UNESP) - Botucatu.

\section{nail Address}

Corresponding author e-mail address Andressa Takahara Montenegro

Rua dos Manacás 100, D19 - Paulínia-SP 13148-312, Brasil.

Phone: +55 (14) 99681-0155

Email: dretakahara@gmail.com

\section{EKeywords}

Brown eggs, egg position, eggshell breaking strength, white eggs.

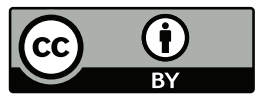

Submitted: 28/February/2019

Approved: 02/May/2019

\section{ABSTRACT}

The objectives of this study were to determine the most suitable probe diameter and egg position to perform the eggshell breaking strength test using a texturometer, as well as the most reliable parameter to estimate eggshell quality when no electronic devices are available. Eggshell quality (eggshell breaking strength, eggshell weight, eggshell percentage, eggshell thickness, shell weight per unit surface area) was evaluated as a function of texturometer probe diameter $(2,10$, and $75 \mathrm{~mm})$, egg type (white and brown) and egg position (horizontal and vertical). In the experiment, 2520 eggs from 60-weekold commercial layers were separated by specific gravity measured by flotation method in saline solution $\left(1.070\right.$ to $1.100 \mathrm{~g} / \mathrm{cm}^{3}$ with intervals of $0.005 \mathrm{~g} / \mathrm{cm}^{3}$ ). Data were submitted to analysis of variance in a completely randomized design, and means were compared by Tukey's test $(p<0.05)$. Correlations between characteristics were calculated using the Pearson's method. The results showed that the most suitable probe diameter for the analysis of eggshell breaking strength was 75 $\mathrm{mm}$, independently of egg positioning or type egg. White eggs should be positioned vertically in relation to the probe, whereas brown can be placed in any position. When it is not possible to evaluate eggshell quality using electronic devices, the measurement of shell weight per unit surface area is recommended.

\section{INTRODUCTION}

Eggshell quality has always been a critical parameter in the egg industry, and has become even more important with the automation of the production system. Eggs with poor eggshell quality cause losses both to the farmers and the egg-processing industries because those eggs cannot be marketed or have low market value, reducing profitability and increasing food waste (Kemps et al., 2006). Therefore, it is essential to regularly evaluate eggshell quality in order to identify problematic flocks and to take corrective actions. To this end, many researchers have developed methods to determine eggshell quality and strength (Jones et al., 2010; Mertens et al., 2010).

The eggshell quality evaluation methods currently applied can be divided in direct methods, which require breaking the eggs, and indirect methods, which do not require eggs to be broken (Roberts, 2004). Indirect methods apply sophisticated equipment, such as texturometers or Digital Egg Tester ${ }^{\circledR}$. Alternatively, simple measurements can be made, including the visual evaluation of eggshell defects and the determination of egg specific gravity, eggshell percentage, eggshell weight per unit of surface area, as well as candling (Coutts et al., 2007; Oliveira \& Oliveira, 2013).

The eggshell protects the eggs during collection, automatic grading, and transportation, and eggshell breaking strength (EBS) is considered 
Montenegro AT, Garcia EA, Molino AB, Cruvinel JM, Ouros CC, Alves KS

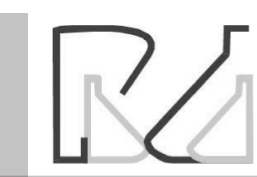

Methods to Evaluate the Eggshell Quality of Table Eggs the most reliable indicator of eggshell quality. The procedure to determine EBS is simple and fast, and is typically made using a texturometer. However, the results may vary according to the diameter of the probe that is used to break the eggs.

Other factors that may also influence EBS evaluation are the compression ratio and response time of the equipment used to determine compression and deformation, as well as eggshell moisture content and even the texture of the surface of the analyzer that is in contact with the egg (Hamilton, 1982). The position of the egg at the time of analysis may also influence EBS determination as the strength applied at the extremities (poles) may be different from that applied the equatorial region of the egg (Jones, 2006).

The texturometer and other electronic analyzers available on the market are expensive, and many producers choose not to acquire them. Thus, eggshell quality assessments can be performed using other existing methods.

In this context, the objective of the present study was to define the most suitable probe diameter and the best egg position to perform the eggshell breaking strength test using a texturometer, and to identify the most reliable eggshell quality parameter to estimate eggshell quality when electronic devices are not available.

\section{MATERIALS AND METHODS}

All the applied procedures were approved by the Committee on Ethics in the Use of Animals - CEUAV FMVZ, process No. 0010/2017.

The experiment was carried out at in the Egg Analysis Laboratory of the School of Veterinary Medicine and Animal Science of São Paulo State University (UNESP), Botucatu, state of São Paulo, Brazil, locate at 22 $51^{\prime} 44^{\prime \prime}$ South latitude and $48^{\circ} 25^{\prime} 47^{\prime \prime}$ West longitude.

A completely randomized experimental design was applied, with three treatments with 30 replicates of one egg each, totaling 2520 eggs. The three treatments consisted of 2-, 10-, or 75-mm probe diameters, two egg types (white or brown) with seven specific gravity values $(1.070,1.075,1.080,1.085,1.090,1.095$ and $\left.1.100 \mathrm{~g} / \mathrm{cm}^{3}\right)$, and broken in two different positions (horizontal and vertical).

The evaluation of the most adequate probe diameter and eggshell quality parameter were based on average egg specific gravity value $\left(1.085 \mathrm{~g} / \mathrm{cm}^{3}\right)$.

Different probe diameters $(2-, 10-$ and $75-\mathrm{mm})$ on the contact surface of the texturometer (model Texture
Analyzer TA.XT Plus, Stable Micro Systems, UK) were tested (Figures1 and 2). Eggs were placed on the flat platform of the equipment always in the same position in order to ensure the standardization of the procedure. A pre-test velocity of $2.0 \mathrm{~mm} / \mathrm{s}$, test speed of $1.0 \mathrm{~mm} / \mathrm{s}$, and post-test velocity of $4.0 \mathrm{~mm} / \mathrm{s}$ were applied.

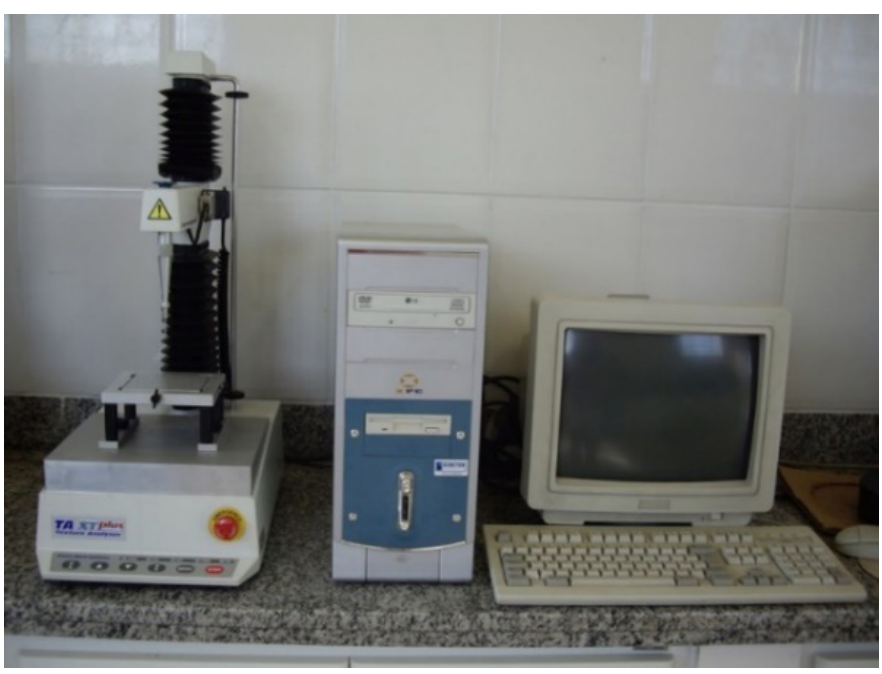

Figure 1 - Texturometer TA. XT Plus of the FMVZ Egg Analysis Laboratory.
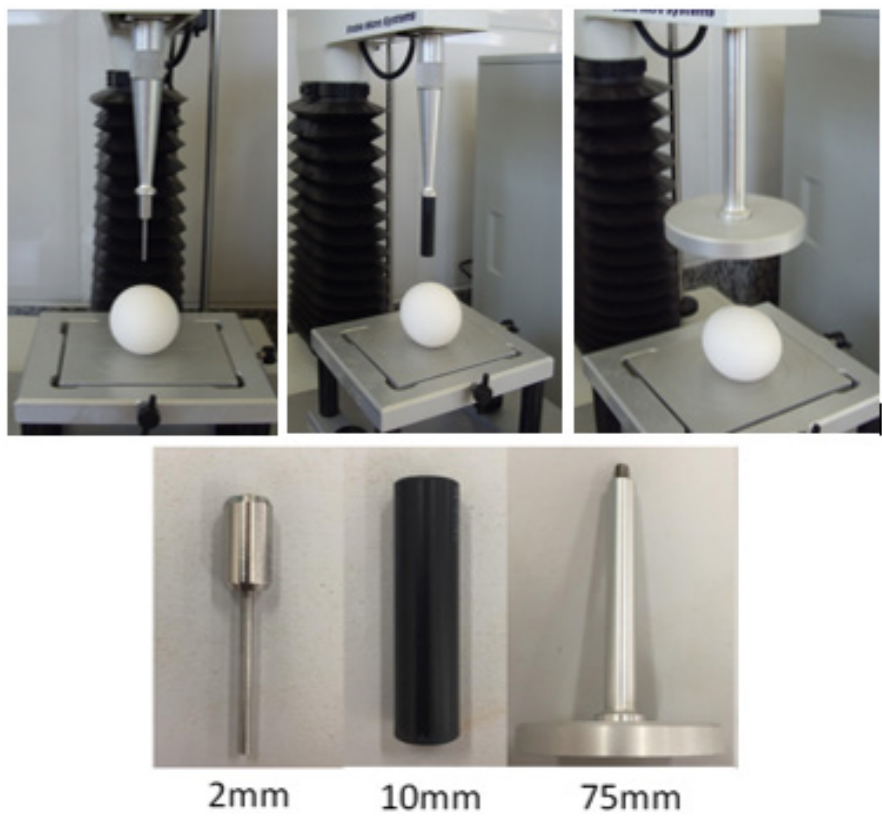

Figure 2 - Probes with 2-, 10-and 75-mm diameter.

Figure 3 shows of the eggs positioned horizontally or vertically at the time of eggshell breaking strength test.

The following characteristics were evaluated: egg specific gravity $\left(E S G ; \mathrm{g} / \mathrm{cm}^{3}\right)$; eggshell breaking strength (EBS; kgf); eggshell weight (ESW; g); eggshell weight relative to egg weight (ESRW; \%), eggshell thickness (EST; mm), and shell weight per unit surface area(SWUSA; mg/(cm²) (Abdallah et al., 1993). 


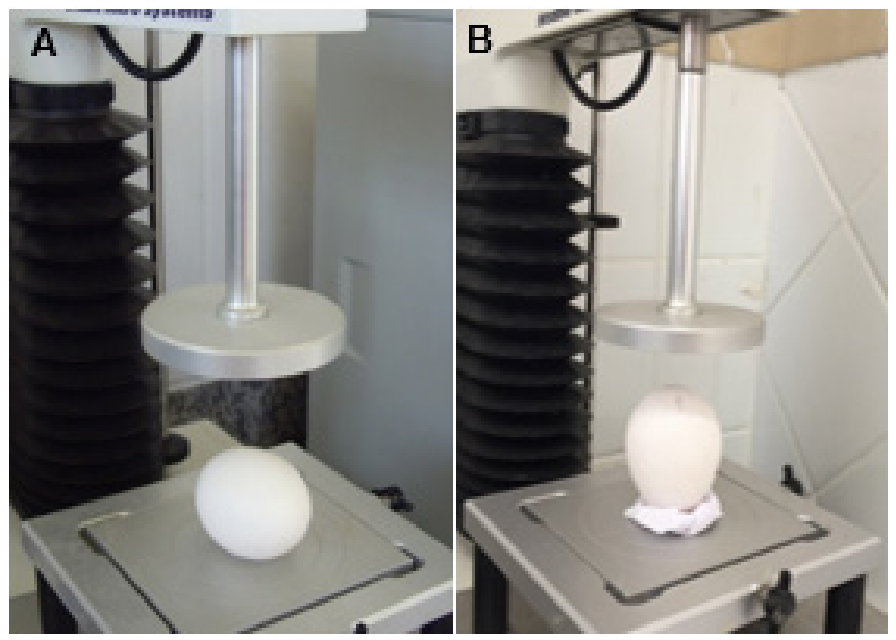

Figure 3 - Egg positioning: (A) horizontal, (B) vertical.

The obtained data were submitted to analysis of variance $(p<0.05)$ according to a completely randomized experiment. Means were compared by the Tukey's test $(p<0.05)$. Correlations between parameters were calculated by the Pearson's method. The SAEG software package was used statistical analyses (UFV, 2000).

\section{RESULTS AND DISCUSSION}

The results below are presented separately according to egg type, white or brown.

Table 1 shows the eggshell quality parameter results of white eggs positioned horizontally and vertically relative to the contact platform of the texturometer as a function of probe diameter.

The only eggshell quality parameter influenced by probe size was eggshell breaking strength (EBS) both in horizontally- and vertically-positioned eggs. This result suggests that EBS is the most accurate indicator of eggshell quality compared with other parameters.

Eggs evaluated using the $2-\mathrm{mm}$ probe showed lower EBS value $(p<0.05)$ compared with the 10 and $75-\mathrm{mm}$ probes in both positions. Possibly, the 10- and 75- $\mathrm{mm}$ probes broke larger eggshell areas than the 2-mm probe. However, although the 75$\mathrm{mm}$ probe is larger than the $10-\mathrm{mm}$ probe, they both probably broke similar surface areas due to the convexity of the eggshell, and therefore generated similar EBS values.

Table 1 - Eggshell quality parameters of white eggs broken in the horizontal and vertical positions.

\begin{tabular}{|c|c|c|c|c|c|c|c|}
\hline \multicolumn{8}{|c|}{ HORIZONTAL } \\
\hline Probes & ESG $\left(\mathrm{g} / \mathrm{cm}^{3}\right)$ & ESW (g) & ESRW (\%) & $\mathrm{EST}(\mathrm{mm})$ & $\begin{array}{c}\text { SWUSA (mg/ } \\
\left.\mathrm{cm}^{2}\right)\end{array}$ & EBS (kgf) & CV $(\%)$ \\
\hline $2 \mathrm{~mm}$ & 1.085 & 5.59 & 9.21 & 0.380 & 77.50 & $2.76 \mathrm{~A}$ & 18.37 \\
\hline $10 \mathrm{~mm}$ & 1.085 & 5.67 & 9.11 & 0.367 & 77.22 & $3.87 \mathrm{~B}$ & 17.06 \\
\hline $75 \mathrm{~mm}$ & 1.085 & 5.75 & 9.11 & 0.363 & 77.57 & $3.52 \mathrm{~B}$ & 14.10 \\
\hline Mean & 1.085 & 5.67 & 9.14 & 0.372 & 77.43 & $3.38 a$ & - \\
\hline CV $(\%)$ & - & 7.56 & 4.63 & 5.84 & 4.60 & 16.77 & - \\
\hline \multicolumn{8}{|c|}{ VERTICAL } \\
\hline Probes & ESG $\left(\mathrm{g} / \mathrm{cm}^{3}\right)$ & ESW (g) & ESRW (\%) & $\mathrm{EST}(\mathrm{mm})$ & $\begin{array}{c}\text { SWUSA (mg/ } \\
\left.\mathrm{cm}^{2}\right)\end{array}$ & EBS (kgf) & CV (\%) \\
\hline $2 \mathrm{~mm}$ & 1.085 & 5.79 & 8.78 & 0.385 & 75.67 & $3.04 \mathrm{~A}$ & 25.82 \\
\hline $10 \mathrm{~mm}$ & 1.085 & 5.85 & 8.71 & 0.391 & 75.47 & $4.33 \mathrm{~B}$ & 16.14 \\
\hline $75 \mathrm{~mm}$ & 1.085 & 6.08 & 8.89 & 0.400 & 77.44 & $4.44 \mathrm{~B}$ & 14.01 \\
\hline Mean & 1.085 & 5.91 & 8.79 & 0.392 & 76.19 & $3.94 b$ & - \\
\hline CV (\%) & - & 16.56 & 15.60 & 16.63 & 15.20 & 34.50 & - \\
\hline
\end{tabular}

Means followed by different uppercase letters in the same column are significantly different among probe diameter; means followed by different lowercase in the same column are significantly different between egg positions by Tukey's test $(p<0.05)$. ESG: Specific gravity, ESW: eggshell weight, ESRW: eggshell weight relative to egg weight, EST: eggshell thickness, SWUSA: shell weight per unit surface area, EBS: eggshell breaking strength. CV: coefficient of variation.

Mean EBS values were significantly higher $(p<0.05)$ in vertically-positioned eggs compared with the horizontally-positioned eggs during the test. This result is in agreement with the findings of Silva et al. (2012), who recorded higher EBS in vertically-positioned eggs from layers submitted to different environmental conditions. Zhang et al. (2016), in a study on the geometric and mechanical properties of goose eggs, also observed that eggs positioned vertically in relation to the probe presented higher EBS values.
These findings may be attributed to the influence of the eggshell structural composition. The structural composition of the eggshell, egg shape, and eggshell thickness are the main factors influencing EBS (Anderson et al., 2004; Bain, 2005). Eggshell thickness is not uniform: eggshells are typically thicker at the sharpend of the egg, and thinner in the equatorial region, where the measurement is performed, whereas the blunt end has intermediate thickness (Abdallah et al., 1993; Baião \& Lúcio, 2005). Rodriguez-Navarro et 
al. (2002) evaluated the microstructures that compose the eggshell and observed that calcite crystals are perpendicularly oriented to the equatorial region of the egg, and that the degree of orientation and size of those crystals directly influenced EBS: eggs with lesser degree of orientation presented higher EBS, and eggshell thickness increased with crystal size, resulting in higher EBS.

Table 2 shows the eggshell quality results obtained in brown eggs positioned horizontally and vertically relative to the contact platform of the texturometer as a function of probe diameter.

Table 2 - Eggshell quality parameters of brown eggs broken in the horizontal and vertical positions.

\begin{tabular}{|c|c|c|c|c|c|c|c|}
\hline \multicolumn{8}{|c|}{ HORIZONTAL } \\
\hline Probes & ESG $\left(\mathrm{g} / \mathrm{cm}^{3}\right)$ & ESW (g) & ESRW (\%) & $\mathrm{EST}(\mathrm{mm})$ & SWUSA $\left(\mathrm{mg} / \mathrm{cm}^{2}\right)$ & EBS (kgf) & CV (\%) \\
\hline $2 \mathrm{~mm}$ & 1.085 & 5.79 & 8.70 & 0.352 & 75.23 & $2.72 \mathrm{~A}$ & 16.16 \\
\hline $10 \mathrm{~mm}$ & 1.085 & 5.71 & 8.66 & 0.356 & 74.66 & $3.40 \mathrm{~B}$ & 16.12 \\
\hline $75 \mathrm{~mm}$ & 1.085 & 5.73 & 8.56 & 0.351 & 74.10 & $3.35 \mathrm{~B}$ & 14.18 \\
\hline Mean & 1.085 & 5.74 & 8.64 & 0.353 & 74.66 & 3.16 & - \\
\hline $\mathrm{CV}(\%)$ & - & 12.97 & 13.26 & 10.25 & 12.66 & 27.11 & - \\
\hline \multicolumn{8}{|c|}{ VERTICAL } \\
\hline Probes & $\mathrm{ESG}\left(\mathrm{g} / \mathrm{cm}^{3}\right)$ & $\mathrm{ESW}(\mathrm{g})$ & ESRW (\%) & $\mathrm{EST}(\mathrm{mm})$ & SWUSA $\left(\mathrm{mg} / \mathrm{cm}^{2}\right)$ & EBS (kgf) & CV (\%) \\
\hline $2 \mathrm{~mm}$ & 1.085 & 5.96 & 8.92 & 0.381 & 77.22 & $2.66 \mathrm{~A}$ & 22.11 \\
\hline $10 \mathrm{~mm}$ & 1.085 & 5.86 & 8.68 & 0.372 & 75.36 & $3.41 \mathrm{~B}$ & 25.99 \\
\hline $75 \mathrm{~mm}$ & 1.085 & 5.94 & 8.80 & 0.367 & 76.34 & $3.48 \mathrm{~B}$ & 15.14 \\
\hline Mean & 1.085 & 5.92 & 8.80 & 0.374 & 76.31 & 3.18 & - \\
\hline CV (\%) & - & 12.21 & 11.56 & 11.21 & 11.08 & 28.26 & - \\
\hline
\end{tabular}

Means followed by different uppercase letters in the same column are significantly different among probe diameter; means followed by different lowercase in the same column are significantly different between egg positions by Tukey's test ( $p<0.05)$. ESG: Specific gravity, ESW: eggshell weight, ESRW: eggshell weight relative to egg weight, EST: eggshell thickness, SWUSA: shell weight per unit surface area, EBS: eggshell breaking strength. CV: coefficient of variation.

The results obtained in brown eggs were similar to those recorded in white eggs. The only eggshell quality parameter that was influenced by probe diameter was EBS, which value was lower $(p<0.05)$ compared with the $10-$ and $75-\mathrm{mm}$ probes.

However, differently from white eggs, the EBS of brown eggs was not affected $(p>0.05)$ by egg positioning in the equipment. It is possible that the brown eggs evaluated in the vertical position were rounder than those in the horizontal position, which may have effectively offset the effect of the positioning factor. Altuntas \& Sekeroglu (2008), evaluating the influence of egg shape on EBS, determined that the eggshell of the more rounded eggs require lower compression force to be broken, and stated that EBS depends on the compression speed, with lower speeds requiring higher compression force.

The calculation of all eggshell quality parameters measured using the texturometer were based on average egg specific gravity. For this reason, the coefficient of variation was zero.

It was also observed that the $75-\mathrm{mm}$ probe provided lower coefficient of variation than the other probe diameters for all evaluated parameters. Greater probe diameters have larger contact areas, providing less variation in the results. If an egg has a more rounded surface, or if a greater diameter probe is used, the contact area with the probe is larger, probably resulting in higher EBS values and lower coefficient of variation. Therefore, the $75-\mathrm{mm}$ probe is the most suitable for this particular analysis.

\section{Correlations between eggshell quality parameters}

As previously mentioned, the objective of this study was to evaluate the correlations among eggshell quality parameters and to identify which has the highest positive correlation with EBS, as this is considered the most reliable indicator of eggshell quality.

The results obtained using the texturometer showed that the most suitable probe diameter to evaluate EBS was $75 \mathrm{~mm}$, and therefore, only the results obtained with the use of this probe are discussed and presented separately according to egg type (white or brown).

Table 3 shows Pearson's correlation coefficients among eggshell quality parameters of white eggs positioned horizontally and vertically in the texturometer.

All evaluated correlations yielded positive values, both in horizontally- and vertically-positioned eggs. These results are in agreement with the positive coefficients obtained by other authors (Frank et al., 1964; Abdalah et al., 1993; Furtado et al., 2001) when evaluating the same eggshell quality parameters in evaluations. 
Table 3 - Coefficients of correlation among eggshell quality parameters of white eggs positioned horizontally and vertically in the texturometer.

\begin{tabular}{|c|c|c|c|c|c|c|}
\hline \multicolumn{7}{|c|}{ HORIZONTAL } \\
\hline & EBS & ESG & ESW & ESRW & EST & SWUSA \\
\hline EBS & - & 0.76 & 0.69 & 0.74 & 0.72 & 0.77 \\
\hline ESG & - & - & 0.73 & 0.89 & 0.87 & 0.88 \\
\hline ESW & - & - & - & 0.75 & 0.76 & 0.87 \\
\hline ESRW & - & - & - & - & 0.90 & 0.98 \\
\hline EST & - & - & - & - & - & 0.91 \\
\hline \multicolumn{7}{|c|}{ VERTICAL } \\
\hline & EBS & ESG & ESW (g) & $\begin{array}{l}\text { E S R W } \\
(\%)\end{array}$ & $\begin{array}{l}\text { E S } \\
(\mathrm{mm})\end{array}$ & SWUSA \\
\hline EBS & - & 0.85 & 0.68 & 0.87 & 0.74 & 0.85 \\
\hline ESG & - & - & 0.70 & 0.96 & 0.83 & 0.93 \\
\hline ESW & - & - & - & 0.75 & 0.82 & 0.88 \\
\hline ESRW & - & - & - & - & 0.86 & 0.97 \\
\hline EST & - & - & - & - & - & 0.90 \\
\hline
\end{tabular}

EBS: eggshell breaking strength, ESG: egg specific gravity, ESW: eggshell weight, ESRW: eggshell weight relative to egg weight, EST: eggshell thickness, SWUSA: shell weight per unit surface area.

In both egg positions, the highest correlation coefficient was obtained between eggshell percentage and shell weight per unit surface area, which was expected, as egg weight and eggshell weight values are used for the calculation of both parameters. The highest coefficient of correlation between ESG and all the other evaluated parameters was shell weight per unit surface area for both egg positions.

When considering the EBS of horizontallypositioned eggs, the highest coefficient of correlation was obtained with shell weight per unit surface area. The second highest coefficient of correlation was with egg specific gravity, followed by eggshell percentage. In vertically-positioned eggs, the highest coefficient of correlation was obtained with eggshell percentage, followed by shell weight per unit surface area and egg specific gravity. These results are in line with and support those observed by other authors. In the study of Narushin et al. (2004), the highest correlation coefficient was obtained between EBS and eggshell percentage. Abdalah et al. (1993), measuring the association of eggshell quality parameters with the percentage of cracked eggs, also found the highest correlation between eggshell percentage and shell weight per unit surface area. In addition, Nordstrom \& Ousterhout (1982) argue that shell weight per unit surface area can be used more efficiently than the other measurements to compare eggshell quality in broiler breeder flocks of different ages.

Table 4 shows the Pearson's correlation coefficients among eggshell quality parameters of brown eggs positioned horizontally and vertically in the texturometer.

As observed in white eggs, positive correlation coefficients were determined between all eggshell quality parameters of brown eggs. The highest correlation coefficient was obtained between shell weight per unit surface area and eggshell percentage. It was also observed that shell weight per unit surface area presented the highest correlation coefficients with all evaluated parameters, independently of egg position.

Table 4 - Coefficients of correlation among eggshell quality parameters of white eggs positioned horizontally and vertically in the texturometer.

\begin{tabular}{|c|c|c|c|c|c|c|}
\hline \multicolumn{7}{|c|}{ HORIZONTAL } \\
\hline & EBS & ESG & ESW & ESRW & EST & SWUSA \\
\hline EBS & - & 0.83 & 0.79 & 0.84 & 0.68 & 0.86 \\
\hline ESG & - & - & 0.81 & 0.97 & 0.74 & 0.96 \\
\hline ESW & - & - & - & 0.83 & 0.80 & 0.91 \\
\hline ESRW & - & - & - & - & 0.76 & 0.99 \\
\hline EST & - & - & - & - & - & 0.80 \\
\hline \multicolumn{7}{|c|}{ VERTICAL } \\
\hline & EBS & ESG & ESW & ESRW & EST & SWAS \\
\hline EBS & - & 0.80 & 0.61 & 0.78 & 0.69 & 0.78 \\
\hline ESG & - & - & 0.61 & 0.85 & 0.70 & 0.83 \\
\hline ESW & - & - & - & 0.71 & 0.74 & 0.85 \\
\hline ESRW & - & - & - & - & 0.77 & 0.97 \\
\hline EST & - & - & - & - & - & 0.81 \\
\hline
\end{tabular}

EBS: eggshell breaking strength, ESG: egg specific gravity, ESW: eggshell weight, ESRW: eggshell weight relative to egg weight, EST: eggshell thickness, SWUSA: shell weight per unit surface area.

In eggs evaluated in the horizontal position, shell weight per unit surface area showed the highest coefficient of correlation with EBS, as observed with horizontally-positioned white eggs, followed by eggshell percentage and egg specific gravity.

When considering EBS of vertically-positioned eggs, the highest coefficient of correlation was obtained with egg specific gravity, followed by shell weight per unit surface area and eggshell percentage, both presenting the same coefficient values.

These results are consistent with those of Charles \& Strong (1988), who showed that egg specific gravity and eggshell percentage can be used to estimate egg shell quality and have a negative correlation with the incidence of broken eggs.

The obtained coefficients of correlation indicate that, independently of egg positioning, all evaluated egg quality parameters are strongly correlated. Therefore, when it is not possible to perform the eggshell breaking strength test, shell weight per unit surface area provides the best estimate of egg quality, particularly in horizontally-positioned eggs, 
which currently is the most commonly egg position used during the eggshell breaking strength evaluation test. Shell weight per unit surface area also showed high correlation with other parameters that strongly influence eggshell quality, and there fore, it is the most suitable parameter to measure eggshell quality when no electronic equipment is not available.

\section{CONCLUSION}

The results of the present study showed that the most suitable probe diameter to analyze egg shell breaking strength is $75 \mathrm{~mm}$, independently of egg positioning or type.

When evaluating egg shell breaking strength of white eggs, it is recommended to position the egg vertically in relation to the contact probe, whereas in brown eggs, either horizontal or vertical positioning can be used.

When it is not possible to evaluate eggshell quality using electronic devices, the measurement of shell weight per unit surface area is recommended.

\section{ACKNOWLEDGEMENT}

The authors express their gratitude to the Foundation for Research Support of the State of São Paulo (FAPESP) (Process No.: 2017/00527-0).

\section{REFERENCES}

Abdallah GA, Harms RH, El-Husseiny O. Various methods of measuring eggshell quality in relation to percentage of cracked eggs. Poultry Science 1993;72(11):2038-2043.

Altuntaş E, Şekeroğlu A. Effect of egg shape index on mechanical properties of chicken eggs. Journal of Food Engineering 2008;85(4):606-612.

Anderson CB, Carter TC. The hens eggs: eggshell cracking at impact on a heavy, stiff body and factors that affect it. British Poultry Science 1976;17(6):613-626

Anderson KE, Tharrington JB, Curtis PA, Jones FT. Eggshell characteristics of eggs from historic strains of single comb white leghorn chickens and the relationship of egg shape to eggshell strength. International Journal of Poultry Science 2004;3(1):17-19.

ABPA - Associação Brasileira de Proteina Animal. Relatório anual 2018. São Paulo. Brasil. 2018. p.17

Baião NC, Lúcio CG. Nutrição de matrizes pesadas. In: Macari M, Mendes AA, editors. Manejo de matrizes de corte. Campinas: Fundação APINCO de Ciência e Tecnologia Avícolas; 2005. p.197-212.

Bain MM. Recent advances in the assessment of eggshell quality and their future application. World's Poultry Science Journal 2005;61(2):268277.

Campos EJ, Soares NM, Gama JRQ, Baião NC. Danos sofridos pela casca durante o manuseio dos ovos de consumo. Anais do $7^{\circ}$ Congresso Brasileiro de Avicultura; 1981; Recife, Pernambuco. Brasil. Recife: UBA; 1981. p. 94-105.
Charles F, Strong JR. Research note: relationship between several measures of eggshell quality and egg-breakage in a commercial processing plant. Poultry Science 1988;68(12):1730-1733.

Coutts JA, Wilson GC, Fernández S, Rosales E, Weber G, Hernández JM. Optimum egg quality: a practical approach. Sheffield: 5M Publishing; 2007

Folkerts J. Influence of feeding and husbandry on egg eggshell quality. Proceeding of the $5^{\text {th }}$ European Poultry Conference; 1976; Malta, Valeta. Europa; 1976. p. 580.

Frank FR, Burger RE, Swanson MH. The relationships among eggshell membrane, selected chemical properties, and the resistance to eggshell failure of Gallus domesticus eggs. Poultry Science 1965;44(1): 63-69.

Furtado IM, Oliveira A, Ferreira DF, Oliveira B, Rodrigues PB. Correlação entre medidas da qualidade de casca e perda de ovos no segundo ciclo de produção. Ciência Agrotécnica 2001;25(3):654-660.

Hamilton RMG. Methods and factors that affect the measurement of egg eggshell quality. Poultry Science 1982;61(10):2022-2039.

Jones DR, Lawrence KC, Yoon SC, Heitschmidt GW. Modified pressure imaging for egg crack detection and resulting egg quality. Poultry Science 2010;89(4):761-765.

Jones DR, Musgrove MT, CaudilL AB, Curtis PA. Frequency of Salmonella Campylobacter, Listeria and Enterobacteriaceae detection in commercially cool water-washed eggshell eggs. Journal of Food Safety 2006;26(4):264-274.

Kemps BJ, Govaerts T, Ketelare B, Martens K, Bamelis FR, BAIN MM, et al. The influence of line and laying period on the relationship between different eggshell and membrane strength parameters. Poultry Science 2006;85(7):1309-1317

Mertens K, Bamelis F, Kemps B, Kamers B, Verhoelst E, DE-Ketelaere B et al. Monitoring of eggshell breakage and eggshell strength in different production chains of consumption eggs. Poultry Science 2006;85(9):1670-1677.

Mertens K, Vaesen I, Loffel J, Kempes B, Kamerns B, Perianu C, Zoons J, et al. The transmission color value: A novel egg quality measure for recording eggshell color used for monitoring the stress and health status of a brown layer flock. Poultry Science 2010;89(3):609-617.

Narushin VG, Van Kepmen TA, Wineland MT, Christensen VL. Comparing infrared spectroscopy and egg size measurements for predicting eggshell quality. Biosystems Engineering 2004;87(3):367-373.

Nordstrom JO, Ousterhout LE. Estimation of eggshell weight and eggshell thickness from egg specific gravity and egg weight. Poultry Science 1982;61(10):1991-1995.

Oliveira BL, Oliveira DD. Qualidade e tecnologia de ovos. Lavras: Editora da Universidade Federal de Lavras; 2013. 223 p

Roberts JR. Factors affecting egg internal quality and egg eggshell quality in laying hens. The Journal of Poultry Science 2004;41(3):161-177.

Rodriguez-Navarro A, Kalin O, Nys I, Garcia-Ruiz JM. Influence of the microstructure on the eggshell strength of eggs laid by hens of different ages. British Poultry Science 2002;43(3):395-403.

Roland DA. The extent of uncollected eggs due to inadequate eggshell. Poultry Science 1977;56(5):1517-1521.

Silva RC, Nascimento JWB, Oliveira DL, Camerini NL, Furtado DA. Força de ruptura da casca do ovo em função das temperaturas da água e do ambiente. Revista Educação Agrícola Superior 2012;27(1):13-18.

Zhang J, Peng W, Tang W, Wang M. Experimental study on the geometrical and mechanical properties of goose eggshells. Revista Brasileira de Ciência Avícola 2016;19(3):455-464 